Jeremy J. Ramsden

\title{
The role of systems thinking in modern society
}

ABSTRACT. Advanced and increasingly complex societies have hitherto managed quite well with their administrators looking for a course of action that is "good enough" (or that satisfices, in the terminology of H.A. Simon), achieved by creating or using a drastically simplified model of the world, taking into account just a few of the factors, those that they regard as most relevant and crucial. The administrator thereby ignores interrelatedness, "so stupefying to thought and action" (Simon). It does not seem too daring to lay the blame for the serial conspicuous administrative failures of recent years at the door of the proponents of satisficing. The Systems Management Panel (SMP), several members of which are presenting papers at the SIMposium, embraces the real complexity of the world and seeks to understand it in such terms, with the aim of providing clear recommendations for practical action to solve seemingly insuperable problems. During the last two years the NHS crisis has been the main focus of attention, and last year the SMP organized a symposium exploring the potential role of smart sensor systems to revolutionize healthcare delivery. Key outcomes of the symposium will be summarized.

Nanotechnology Perceptions 14 (2018) 90-98

doi: 10.4024/N11RA18A.ntp.14.02 